\title{
A Perspective on Roles Played by Immunosenescence in the Pathobiology of Alzheimer's Disease
}

\author{
Yan Zhao, Jun-Kun Zhan, Youshuo Liu* \\ Department of Geriatrics, Institute of Aging and Geriatrics, the Second Xiangya Hospital, Central South \\ University, Changsha, Hunan 410011, China
}

[Received December 19, 2019; Revised February 2, 2020; Accepted February 5, 2020]

\begin{abstract}
Alzheimer's disease (AD) is a chronic progressive neurodegenerative disorder. Aging is the most significant risk factor for late-onset AD. The age-associated changes in the immune system are termed immunosenescence. A close connection between immunosenescence and AD is increasingly recognized. This article provides an overview of immunosenescence and evidence for its role in the pathogenesis of AD and possible mechanisms as well as the outlook for drug development.
\end{abstract}

Key words: immunosenescence, Alzheimer's disease, inflammation, aging

\section{Introduction}

Alzheimer's disease $(\mathrm{AD})$ is the most common type of dementia characterized by progressive memory loss, visual-spatial impairment, executive dysfunction, and personality and behavioral changes. According to the "Word Alzheimer Report 2018", there are nearly 50 million AD patients worldwide in 2018, and this number is expected to increase to 152 million by 2050 . The pathological features of $\mathrm{AD}$ are neuritic plaques, neurofibrillary tangles, neuronal and synaptic loss, and the activation of microglia [1]. Over the past few decades, the amyloid cascade hypothesis has dominated the field of $A D$ research, suggesting that $A \beta$ deposition is the central event in $\mathrm{AD}$ pathology [2]. However, recent findings have challenged this hypothesis and argue that $\mathrm{A} \beta$ protects the brain from infection, and its aggregation promotes microglia-mediated neuroinflammation [3]. The viewpoint that altered immune and inflammatory responses may play the main role in the progression of $\mathrm{AD}$ has increasingly been recognized $[4,5]$.
Aging is characterized by a time-dependent loss of anatomic and physiological integrity,resulting in increased vulnerability to some diseases and death [6]. Induced by genetic, epigenetic, and environmental factors [7], aging affects almost all organs and has a profound impact on the immune system [8]. AD is the most common type of age-related neuronal disorder[9]. It is hypothesized that $\mathrm{AD}$ pathology is regulated by the immune system in an age-dependent manner [10].

In recent years, research is making significant progress and proposes that immunosenescence actively participates in the pathogenesis of $\mathrm{AD}$ and mediates inflammatory damage. However, it is still unclear how specific changes in the immune system with aging affect the central nervous system (CNS) and cause AD. In this review, we provide an overview of changes in the immune system with aging, but this is not a comprehensive review of immunosenescence. We mainly discuss the changes related to $\mathrm{AD}$ and improvement strategies.

*Correspondence should be addressed to: Dr. You-Shuo Liu, the Second Xiangya Hospital, Central South University, Changsha, Hunan 410011, China. E-mail: liuyoushuo@csu.edu.cn

Copyright: ( 2020 Zhao Y et al. This is an open-access article distributed under the terms of the Creative Commons Attribution License, which permits unrestricted use, distribution, and reproduction in any medium, provided the original author and source are credited. 


\section{Immunosenescence}

The immune system is responsible for preventing the invasion of pathogens and removing damaged or harmful cells, like senescent cells and toxic substances. Immunosenescence includes degeneration of immune organs, aging-related changes in the phenotype and function of immune cell subsets, and chronic inflammatory states. Although immunosenescence occurs in almost all aged people, differences in genetics, environment, lifestyle, and nutrition cause heterogeneity among different individuals, making some people more susceptible to developing certain diseases [11]. For example, immunity is relatively stable in some populations, retaining more young immunological parameters. Offspring of Sicilian centenarians found that they retained more young immune parameters, suggesting that genetic or environmental factors can delay immunosenescence[11]. A growing body of studies has provided supportive evidence for the role of immunosenescence in contributing to $\operatorname{AD}[12,13]$.

\section{Roles played by immunosenescence of innate immune in the pathology of $\mathrm{AD}$}

\subsection{Immune Barrier}

The immune barrier is a physiological and anatomical structure that prevents pathogens or molecules from entering the body or parts of the body. It is an important component of non-specific immune function and is the first line of defense. The immune barriers include skin, respiratory mucosa, digestive tract mucosa, placental barrier and blood-brain barrier (BBB), etc. The immune barrier plays a protective role through a physical barrier, chemical killing and bio-antagonism. Aging leads to barrier dysfunction and increases the challenge of the innate immune system in the elderly. Living together with diverse microbes, there are trillions of microbes in our tissues such as intestines and lungs and other tissues.Recent studies have revealed the dynamic interaction between the microbiota and the immune system, as well as the pathogenic results of maladjustment [14].

\subsubsection{Gut barrier}

The gut barrier is a structure that separates the environment and the host's interior, and regulates the selective passage of substances, as well as promotes the absorption of nutrients, while prevents the invasion of pathogens and other toxic substances from entering the human body [15]. Under homeostatic conditions, gut microorganisms regulate mucus secretion and enhance the integrity of the intestinal barrier by producing shortchain fatty acids [16]. Lymphocytes such as Th17 participate in host defense responses by producing IL-22. Epithelial cells produce antimicrobial peptides under the stimulation of interleukins [16]. Dendritic cells induce the activation and differentiation of naive $B$ cells to produce plasma cells that secrete specific $\operatorname{IgA}$ in the lamina propria [17]. IgA is transported into the gut lumen in the form of sIgA, which binds to commensal microorganisms and soluble antigens, inhibiting their adhesion to epithelial cell surfaces and intestinal barrier penetration [18].

An important feature of the alimentary tract is immune tolerance, allowing certain bacteria to reside in specific areas [19]. However, if any of these resident bacteria migrate to other places, it may present a potential hazard [20]. In addition to actively selecting a more suitable environment, bacteria may also accumulate due to immunosenescence [20]. Studies have attempted to explore the connection between aging and the gut barrier, which found that permeability of the intestinal barrier changed with age. Changes in contractile force and innervation of the intestinal smooth muscle of elderly rodents [21], as well as increased permeability of the intestinal tract to macromolecules [22], indicate that aging is associated with deterioration in the function and integrity of the intestinal barrier. In the aging population, the altered microbiota composition leads to increased adhesion and leakage of microorganisms and microbial by-products through the gut barrier,eventually causing the occurrence of disease [23]. The gut microflora of the elderly is different from that of the healthy adults, which is partly due to aging, such as weakened immunity, physiological and morphological changes in the gut, altered lifestyle and dietary structure, etc [23, 24]. Agerelated changes in the microbial-intestinal-brain axis lead to increased circulating inflammatory factors, which can also be seen in mice [25].

Researchers have found that intestinal flora is closely linked to diseases such as metabolic diseases, autism, depression, Parkinson's disease(PD), and AD [26]. In 2016, scientists confirmed for the first time the link between the intestinal flora and PD and found that the production of short-chain fatty acids by the intestinal flora can activate brain microglia, which causes neuroinflammation and neuronal damage [27]. This year, researchers at Johns Hopkins University in the United States confirmed that misfolded $\alpha$-synuclein can travel from the small intestine to the brain along the vagus nerve, and it can prevent $\alpha$-synuclein from entering the brain by cutting off the vagus nerve, which may become the key to prevent PD [28].

To explore the correlation between microbial flora and $\mathrm{AD}$, the intestinal microbiota of $\mathrm{AD}$ patients and age- 
and sex-matched control individuals was investigated. The $\mathrm{AD}$ group has reduced microbial diversity and has a unique bacterial genus, which related to changes in cerebrospinal fluid (CSF) biomarkers [29]. Neuropathological studies found that the levels of LPS and $E$. coli $\mathrm{K} 99$ pili protein were higher in AD brain parenchyma compared to controls[30]. What's more, LPS colocalized with $A \beta$ in amyloid plaques and vessel walls in $A D$ brains, suggesting that the displacement of the intestinal flora may occur in $\mathrm{AD}$ patients [30].

How do intestinal pathogens enter the brain tissue? One possibility is that the gut microbes and highly proinflammatory neurotoxins reach the circulation from the gut mucosa by a special adhesion structure, and then enter tissues and organs, including the brain tissue[31]. Microorganisms may also reach the brain tissue through the vagus nerve, causing a series of pathological changes.Among these mechanisms, direct regulation of gut microbiota may reduce the inflammatory response and improve immune response, and finally prevent disease [32].

\subsubsection{Oral and nasal mucosa}

A large number of bacteria are found in the oral and nasal mucosa, and various types of bacteria form a complex ecosystem [33]. There is a dynamic equilibrium between bacteria in dental plaque and host immunity [34]. Bacterial load is likely to increase with age [35]. Increasing evidence suggests that there is a link between $\mathrm{AD}$ and periodontitis. On the one hand, $\mathrm{AD}$ patients are more susceptible to periodontitis. On the other hand, patients with periodontitis are more likely to suffer from AD than those with a healthy periodontal condition, and the severity of periodontitis is positively correlated with the decline in cognitive impairment [36]. A meta-analysis in 2017 showed that the risk of $\mathrm{AD}$ in patients with periodontitis was almost three times that of nonperiodontitis patients, and the oral health performance of $\mathrm{AD}$ patients was also worse than that of non-AD patients [37]. Periodontitis may affect the brain through intact pathogenic microorganisms or inflammatory mediators. Some nerves originate from brain tissue and distribute in the oral or nasal mucosa, including the trigeminal and olfactory nerves. The pathogens or other harmful molecules may invade the CNS along the olfactory pathway or the trigeminal nerve, or enter the systemic circulation through the mucous membrane and finally reach the CNS [38]. It has been confirmed that there is oral Treponema in the trigeminal nerve and may be the pathway for oral pathogens in $\mathrm{AD}$ to enter the brain [39]. Olfactory ensheathing cells (OECs) provide bactericidal protection against invasion of pathogenic microorganisms from the nose and mouth [39]. They have macrophage-like functions such as expressing inducible carbon monoxide synthase when attacked, and then engulf bacteria and migrate [39]. OECs have been proven to bypass the BBB and successfully transfer drugs containing nanoparticles to the brain [40]. The above evidence suggests that it may act as a channel for pathogens or other environmental stimuli to enter, and then spread through the olfactory pathway to pathological changes throughout the brain.

\subsubsection{BBB}

BBB is a highly selective barrier between blood and brain tissue, which restricts the uncontrolled diffusion of cells and molecules from the blood into CNS, and regulates nutrients into brain tissue [41]. In the context of aging or disease, potentially harmful proteins may penetrate the brain through the damaged BBB [42]. Recent evidence shows that $\mathrm{BBB}$ breakdown occurs in healthy aging, and is worse in individuals with mild cognitive impairment [42]. BBB disruption is considered a biomarker of early cognitive damage, which is independent of $A \beta$ and tau pathology [43].

Tight junction proteins connect the endothelial cells of brain capillaries,preventing molecules in the plasma from entering the brain [44]. Reduced expression of tight junctions (TJs) in aged mice inhibits the communication between endothelial cells and increases the permeability of BBB [45]. Overactivation of the peripheral immune system, determines the increased release of proinflammatory cytokines and chemokines, and up-regulate the expression of immune receptors. These immune molecules, reach the CNS through the damaged BBB, causing brain tissue damage [46]. During AD pathology, damaged brain and high permeability of BBB determine that peripheral immune cells may participate in CNS immune response, as autopsy showed that $\mathrm{T}$ cells infiltrated into brain tissue [47]. Besides, monocytes also enter the brain through BBB to form macrophages or dendritic cells, with different states of activation[48]. Integrity destruction of $\mathrm{BBB}$ in $\mathrm{AD}$ patients partly reveals the clues of migration of peripheral immune cells to the damaged brain [49].

There are transport systems on the BBB that mediate the transfer of $A \beta$ into and out of the brain. P-gp and LRP-1 are important efflux transporters that mediate the clearance of $A \beta$ from brain tissue [50]. P-gp function decreased in both aged humans $[51,52]$ and in aged mice [53]. The expression level of LRP1 is reduced in cerebrovascular endothelial cells in normal aging and $\mathrm{AD}$ patients [54]. Further study showed that the expression level of LRP1 in microvasculature was negatively correlated with $A \beta$ accumulation [54]. Collectively, these 
changes of transporters on BBB with age may lead to the accumulation of $A \beta$ in the $A D$ brain.

Glucose is the most important energy source for brain tissue. Glucose transporter 1 (GLUT1) on BBB vascular endothelial cells, a unidirectional transporter, is a receptor for glucose transport [55]. Studies have shown that the reduction in glucose uptake by the brain could reflect the dysfunction of BBB [56]. GLUT1 reduction at $\mathrm{BBB}$ was found in 15-month-old mice, and reduce more in AD models of the same age [57]. PET-CT can measure the brain glucose uptake, and there is reduced glucose uptake in the frontal and temporal lobe of the elderly [58]. Aged rodents also show a reduction of brain glucose uptake, which is related to cognitive impairment [59].

Increased BBB permeability with age makes it possible for microorganisms and their products to enter the CNS. At the same time, changes in multiple transporters expressed on aged BBB lead to malabsorption of nutrients and reduced $A \beta$ efflux, eventually contribute to the pathology of $\mathrm{AD}$.

\subsubsection{Choroid plexus}

Choroid plexus (CP), as the site of the blood-CSF barrier, is recognized to provide a protective effort for the brain. Due to its anatomical structure and physiological characteristics, $\mathrm{CP}$ restricts the migration of immune cells and plays an important role in maintaining brain homeostasis.In the $\mathrm{CP}$ matrix, researchers have found almost all kinds of immune cells, and the traffic of these cells depends on signals generated by the CNS, such as TNFa and IFN $\gamma$ [60]. In aging CP, an increased Th1:Th2 ratio leads to increased expression of the chemokine CCL11 and decreased permeability to leukocytes [61]. Besides, CCL11 is thought to promote the transformation of microglia into an inflammatory state [62], which is associated with cognitive impairment. Furthermore, it was found that the anti-inflammatory factor IL-4 was elevated in the aging $\mathrm{CP}$, which induces the $\mathrm{CP}$ epithelial cells to produce more CCL11 [62]. Another study by the same team showed that an increase of IFN1 in CP in aged mice offsets the effects of CCL11 and reduces age-related chronic inflammatory processes [63]. Therefore, we speculate that aging affects the balance of peripheral immune cells that homing to the brain and thus participates in the regulation of CNS function.

During disease progression, researchers found that IFN $\gamma$ levels at the CP decreased in $5 \times$ FAD mice, APP/PS1 mice and brain aging [64], as well as other neurodegenerative diseases [65]. IFN $\gamma$ is mainly produced by Th1 cells, and Tregs can inhibit Th1 cell function [64]. By transient Treg depletion, the IFN $\gamma$ signal pathway in $\mathrm{CP}$ is restored, which increases peripheral immune cells transfer to the brain parenchyma that may clear $A \beta$, and finally improve memory and behavioral disorders [66]. The above results show that the selective trafficking of immune cells via the $\mathrm{CP}$ is one of the underlying mechanisms of pathological changes in neurodegenerative diseases [67].

\subsection{Immunosenescence of innate immune cells Microglia}

Microglia are innate immune cells that reside in the brain and play an important role in maintaining homeostasis and immune defense [68]. When there are no harmful stimuli, the microglia remain stationary, with poor replication ability. Although in a relatively static state, they still extend and retract their protuberances to screen and respond to dangerous challenges [69].

Microglia undergo significant changes in the aging brain. Morphologically, aged microglia exhibit cytoplasmic hypertrophy and branch reduction [70]. Functionally, senescent microglia show higher proliferative capacity and production of proinflammatory cytokines, but reduced chemotaxis and ability to clear $\mathrm{A} \beta$ [71]. After peripheral injection of lipopolysaccharide, aged mice showed increased expression of proinflammatory factors and increased activity of microglia [72]. In addition, in vitro experiments revealed that senescent microglia secrete more TNF- $\alpha$ and IL-6 than that of young mice [73].

Activated and proliferated microglia surround amyloid plaques in the $\mathrm{AD}$ brain and participate in the clearance of $A \beta$ [74]. Microglia clear the dissolved $A \beta$ via a pinocytosis form or an LDL receptor-associated protein-mediated pathway [75]. Insoluble $A \beta$ binds to the receptors on the surface of microglial cell membrane. $A \beta$ binds to TLRs, RAGE and other receptors on the surface of microglia membranes, transducing intracellular signaling pathways, then leading to the synthesis and release of pro-inflammatory factors [75]. In the aging brain, the phagocytic capacity of microglia is weakened, which leads to the accumulation of $A \beta$. Microglia continue to activate, leading to chronic inflammation, increased oxygen free radicals, mitochondrial damage, and ultimately neuronal death [76].

\section{Monocyte/Macrophage}

Monocytes can differentiate into macrophages, dendritic cells, and antigen-presenting cells. Infiltrating monocytes express pattern recognition receptors that detect substances released by damaged CNS cells or recognize surface antigens of invade pathogens [69]. Upon recognition of these molecules, a pro-inflammatory signaling cascade can be induced, and infiltrating monocytes acquire an activated phenotype, exhibiting a 
cytoplasmic enlarged amoeba morphology [77]. During aging, both microglia and macrophages have defects in phagocytosis and chemotaxis [78]. As to proinflammatory response, senescent macrophages appear unlikely to produce functional pro-inflammatory responses [69].

The exact source of amoebic myeloid cells surrounding amyloid plaques has been controversial due to the technical challenge of identifying invasive myeloid cells and locally activated microglia. Recent evidence suggests that peripherally derived macrophages maintain unique functional and transcriptional features in the CNS [79]. After entering the AD brain, monocytes become the most important cells that phagocytose A $\beta$ [80]. Monocyte-derived macrophages are very effective in binding to $A \beta$, as confocal microscopy revealed that the MHC-II/A $\beta 42$ complexes were only present on AD monocytes/macrophages [81]. Activated macrophages exhibit two phenotypes, namely M1 and M2, depending on the local microenvironment [82]. M1 produces proinflammatory factors and M2 is associated with the production of regulatory or anti-inflammatory factors [69]. M1 and M2 are balanced in healthy people, but in the presence of inflamm-aging, there is an imbalance,contributing to age-related disease development [83]. Researchers proposed macrophages as key cells in the induction and maintenance of inflammaging [84]. Under the induction of $A \beta$, macrophages change their phenotype M2 to phenotype M1, which produces IL-1b and TNFa. Macrophages interact with microglia and amyloid plaques and are thought to be inflammatory activators that produce cytokines and reactive oxygen species (ROS), leading to neuronal loss and apoptosis [34].

\section{Natural killer cells}

NK cells, different from T cells and B cells, are defined as innate cytotoxic lymphocytes [85]. According to the expression of phenotypes and functional markers, NK cells are divided into two types: CD56 $6^{\text {bright }}$ and CD56 $6^{\mathrm{dim}}$ [86]. CD56 $6^{\text {bright }}$ has an immunomodulatory role and can produce high levels of cytokines and chemokines [87]. $3 \mathrm{xTgAD}$ mice developed premature immunosenescence at 4 months of age, while NK percentage and cytotoxic activity changed at the age of 2 months, well before amyloid plaques and cognitive impairment [88]. There is no difference in the distribution of NK cells in the agematched healthy elderly patients with $\mathrm{AD}$, but the phenotype and function of NK cells have changed in the amnestic MCI (early stage of AD), showing the activation state and excessive cytokine secretion [89]. Changes of NK cells may be one of the peripheral markers in the preclinical or prodromal phase of $\mathrm{AD}$ [90].

\section{Roles played by immunosenescence of adaptive immune in the pathology of $\mathrm{AD}$}

In contrast to the activation of innate immunity,adaptive immunity appears to be much less prominent in $\mathrm{AD}$ pathology [91]. The main cellular components of adaptive immunity are $\mathrm{T}$ and $\mathrm{B}$ lymphocytes. The adaptive immune response plays a key role in the development of control against pathogens and toxic molecules including misfolded tau and $\mathrm{A} \beta$ proteins [92].

\subsection{T cells}

$\mathrm{T}$ cells are mainly involved in cellular immune response, which is important for anti-tumor, transplant rejection and delayed-type hypersensitivity. $T$ cells and their secreted cytokines are important for protecting brain function homeostasis. A series of studies have established the ability of $\mathrm{CD}^{+} \mathrm{T}$ cells to maintain cognition and behavior in naive mice, especially $\mathrm{CD}^{+} \mathrm{Th}$ cells and their secreted cytokines, which promote memory function and social behavior [34]. Among them, IFN $\gamma$ produced by $\mathrm{CD} 4^{+} \mathrm{Th} 1$ cells residing in the meninges supports neural circuits and is very important for social behavior [93]. IL-4 produced by $\mathrm{CD}^{+}{ }^{+} \mathrm{Th} 2$ regulates meningeal dendritic cells and stimulates astrocytes to produce BDNF, which promotes learning ability [94].

Senescent $\mathrm{T}$ cells have fewer $\mathrm{T}$ cell receptors and may turn into dysfunctional "virtual memory" cell phenotypes [95]. In vitro studies indicated that $\mathrm{CD}^{+}$ naive $T$ cells derived from the elderly and aged mice have decreased proliferative activity, altered ability to secrete cytokines, and reduced reactivity to TCR stimulation [96]. Similarly, aging will affect the ability of $\mathrm{CD} 8^{+} \mathrm{T}$ cells to aggregate. Another important feature of immunosenescence of $\mathrm{T}$ cells is the increase in highly differentiated memory $\mathrm{CD} 8^{+}$cells stimulated by chronic viruses such as CMV [96]. Terminally differentiated senescent $\mathrm{T}$ cell expansion, and over expression of cytokines and pro-inflammatory factors, will result in a host with high inflammatory response [34]. Compared with middle-aged control individuals, A $\beta$-reactive T cells were easily detectable in the peripheral blood of $\mathrm{AD}$ patients and healthy elderly subjects [97]. Spleen is the biggest peripheral immune organ. It was noted that there was a higher frequency of Tregs in splenocytes derived from old transgenic mice [98]. Transient depletion of Foxp $^{+}$Tregs or pharmacological inhibition of Treg activity was associated with reduced neuroinflammatory response, amyloid plaque clearance and cognitive improvement [99]. Treg depletion was also shown to influence the choroid plexus and as such affect CNS traffic of immune cell that included Tregs and monocytederived macrophages to plaque sites [100-101]. 


\subsection{B cells}

B cells are the only cells that produce antibodies, and they are also full-time antigen-presenting cells. Immunosenescence of B cell is characterized by less receptor diversity and weakened ability to convert to memory B cells, along with reduced antibodies response to antigens [102]. The decrease of antibody specificity and affinity affected by age will increase the susceptibility of diseases in the elderly [103]. What's more, the ability of B cells to convert $\operatorname{IgM}$ to $\operatorname{IgG}, \operatorname{IgE}$ or $\operatorname{IgA}$ is reduced during aging, both in humans and mouse models [104]. A specific set of mature B-lymphocyte subsets related to age may aggregate in elderly individuals, which may promote inflammation and autoimmune response [34].

Table 1. Alterations in the cellular components of innate and adaptive immunity associated with aging.

\begin{tabular}{|c|c|c|}
\hline $\begin{array}{l}\text { Immune cells or their } \\
\text { products }\end{array}$ & $\begin{array}{l}\text { Changes related to AD } \\
\text { pathology }\end{array}$ & Ref. \\
\hline \multicolumn{3}{|l|}{ Innate immunity } \\
\hline \multirow[t]{2}{*}{ Microglia } & $\begin{array}{l}\text { Ability to phagocytose } \\
\text { A } \beta \text { fibrils } \downarrow\end{array}$ & [71] \\
\hline & $\begin{array}{l}\text { Production of } \\
\text { proinflammatory } \\
\text { cytokines } \uparrow\end{array}$ & {$[72,73]$} \\
\hline \multirow[t]{3}{*}{ Monocyte/Macrophage } & $\begin{array}{l}\text { Functional } \\
\text { proinflammatory } \\
\text { response } \downarrow\end{array}$ & [69] \\
\hline & $\begin{array}{l}\text { Phagocytosis and } \\
\text { chemotaxis } \downarrow\end{array}$ & {$[78]$} \\
\hline & $\begin{array}{l}\text { The imbalance between } \\
\text { M1 and M } 2 \uparrow\end{array}$ & [83] \\
\hline Natural killer cells & $\begin{array}{l}\text { Number of NK cells and } \\
\text { cytotoxic activity } \downarrow\end{array}$ & {$[88]$} \\
\hline \multicolumn{3}{|l|}{ Adaptive immunity } \\
\hline \multicolumn{3}{|l|}{$\mathrm{T}$ cells } \\
\hline $\mathrm{Th} 1 / \mathrm{IFN} \gamma$ & $\begin{array}{l}\text { IFN } \gamma \text { signaling activation } \\
\text { supports neural circuits } \downarrow\end{array}$ & [93] \\
\hline Th2/IL-4 & $\begin{array}{l}\text { IL- } 4 \text { stimulates astrocytes } \\
\text { to produce BDNF } \downarrow\end{array}$ & [94] \\
\hline Treg cells & Frequency of Treg cells $\uparrow$ & {$[98]$} \\
\hline \multirow[t]{2}{*}{ B cells } & $\begin{array}{l}\text { Antibody specificity and } \\
\text { affinity } \downarrow\end{array}$ & [103] \\
\hline & $\mathrm{A} \beta$ antibody levels $\downarrow$ & {$[108]$} \\
\hline
\end{tabular}

The research on whether $\mathrm{B}$ cells participate in the pathogenesis of $\mathrm{AD}$ is limited. Reductions in the number of peripheral $B$ cell subsets were found in some $A D$ patients [105]. Misfolded A $\beta$ peptides have been shown to induce $\mathrm{B}$ cell-mediated immune responses,generating autoantibodies against $A \beta$ being found in the CSF and blood [106]. These autoantibodies seem to share conformation-specific binding epitopes and promote microglia-mediated clearance of amyloid plaques [107]. There are antibodies against different forms of $A \beta$ in healthy individuals, and these antibody levels decrease with normal aging. In addition,with aggravation of $\mathrm{AD}$, the downward trend is more pronounced [108]. In the acute phase of CAA-RI, anti-A $\beta$ antibodies are elevated, and after clinical remission, autoantibodies gradually decrease,suggesting that the effect of B cells on amyloid pathology is complex [109].

In summary, age-related changes in innate and adaptive immune cells and their secreted cytokines are involved in the pathogenesis of $\mathrm{AD}$ (Table 1).

\section{Inflamm-aging in $\mathrm{AD}$}

Inflammation, a normal repair response, is crucial to combat pathogens and clear dead cells. The initiation and dissipation of physiological inflammatory responses are strictly regulated [110]. Once the inflammation is dysregulated, it will cause tissue damage. Inflamm-aging refers to a state of chronic pro-inflammatory response in the process of aging,which is controllable, asymptomatic, chronic and systemic, and is considered to be a part of immunosenescence [111]. The basis of inflamm-aging is the remodeling of the immune system, characterized by increased levels of cytokines and other pro-inflammatory markers in the circulation [112], such as a 2-4 fold increase in serum IL-6 and CRP [113].

$\mathrm{AD}$ is also considered to be a chronic inflammatory disease. The inflammatory response of AD is not limited in the brain, but also exists in peripheral tissues, which is considered to be part of the systemic inflammatory response [60]. In $\mathrm{AD}$ mice, it was found that elevated levels of pro-inflammatory factors in the circulation are significantly associated with cognitive decline [114]. A prospective study of 1633 participants showed a positive correlation between peripheral inflammatory response in middle age and late brain volume reduction [115]. AD often coexists with chronic inflammatory diseases such as diabetes mellitus and rheumatoid arthritis (RA) and psoriasis [116]. TNFa is a key cytokine that drives the pathogenesis of RA, and RA patients reduce the risk of $\mathrm{AD}$ after receiving anti-inflammatory treatment [117]. At the same time, peripheral neutralization of TNFa is considered to be effective in animal models of AD.

The chronic inflammatory state in aging individuals may be associated with long-term chronic microbial infections, which may be a driver of cognitive decline and possibly dementia in the elderly [118]. Candidate pathogens proposed over the years include herpes simplex virus type $1(\mathrm{HSV}-1)$, herpes simplex virus type 2 (HSV-2), human herpesvirus 4 (HHV-4), human herpesvirus 5 (HHV-5), human herpesvirus 6 (HHV-6) and 7 (HHV-7), intestinal bacteria (H.pylori), periodontal bacteria (P.gingivalis), spirochetes (B.burgdorferi) and other bacteria [119]. These pathogens may invade CNS via the trigeminal nerve, olfactory nerve, gastrointestinal 
tract, and BBB. They also cause an inflammatory reaction in the periphery, which circulates to the brain through the blood, causing central inflammation [38].

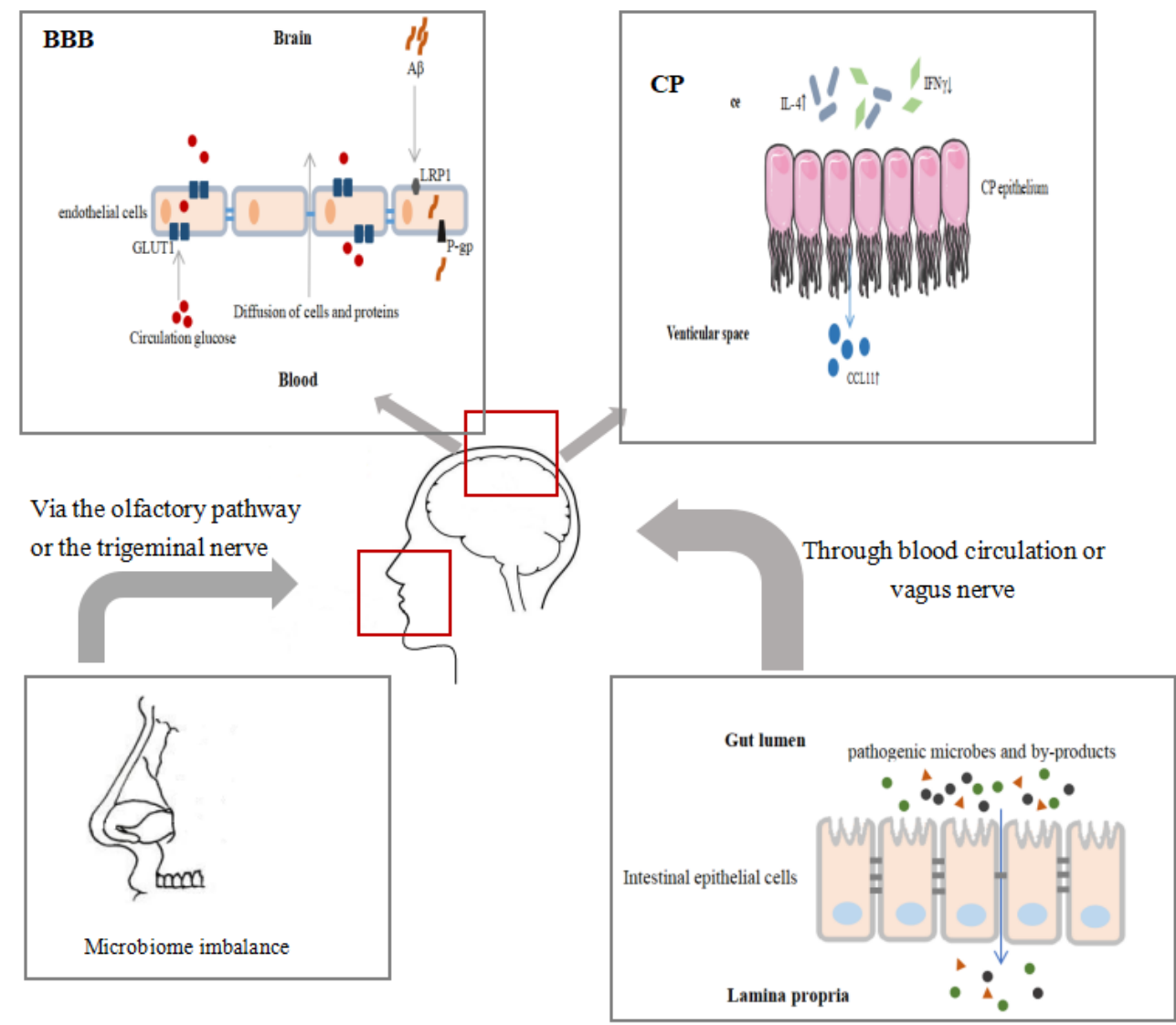

Figure 1. Schematic representation of age-related changes of immune barriers. Studies have shown that changes in immune barriers such as permeability and receptor expression, increasing challenges of the innate immune system, which are associated with the pathology of AD. Selective trafficking of immune cells via the immune barrier is also one of the underlying mechanisms of pathological changes in neurodegenerative diseases.

\section{Novel treatments for AD}

There is no disease-modifying drug available for AD, and current symptomatic treatment provides limited help.As described above,we put forward the possibility that immunosenescence is a contributing cause of $\mathrm{AD}$. Reversing immunosenescence to restore immune protection in the CNS is a promising strategy for $\mathrm{AD}$ therapy (Fig. 1).

\subsection{Antibacterial and antiviral treatment}

Alzheimer's disease has been thought to be associated with viral or bacterial infections for a long time and is supported by increasing evidence [120]. Pathogen invasion into the brain may act as a trigger or aggravating factor for $\mathrm{AD}$. As mentioned above, pathogens in the mouth, nose or intestines may enter the CNS through the damaged intestinal barrier, oral and nasal mucosa, or neural access (Fig. 2). In addition, chronic microbial infection releases pro-inflammatory substances, which reach vascular circulation and cross $\mathrm{BBB}$ to cause neuroinflammation [34]. In AD mouse and worm models, $\mathrm{A} \beta$ can aggregate into a network to prevent Salmonella or Candida infection [121]. Long-term broad-spectrum antibiotic treatment reduces amyloid plaque in APP/PS 1 mice and attenuates the local glial reactivity around plaques, as well as alters the morphology of microglia [122]. Numerous studies have demonstrated the key role of gut dysbiosis in neurodegeneration. Disturbances along the brain-gut-microbiota axis may be involved in the pathogenesis of AD [123]. GV-971, a new drug 
approved in 2019 in China to treat AD, can regulate gut flora imbalance and reshape immune homeostasis. It can also prevent the infiltration of peripheral immune cells into the brain, inhibit neuroinflammation and prevent the progression of AD [124]. Treatment with antivirals and/or antibacterials may alleviate $\mathrm{AD}$ pathology. Studies found that antiviral therapy in subjects with HHV-5 or HSV could be beneficial in reducing the incidence of $\mathrm{AD}[125,126]$. However, there is no epidemiological data suggest the hypothesis that antibiotic use decreases the risk of $\mathrm{AD}$ onset. But if we know which bacterial plural are overexpressed in the mouth, nasal cavity and gut of AD patient, suitable antimicrobial agents may benefit them [127].

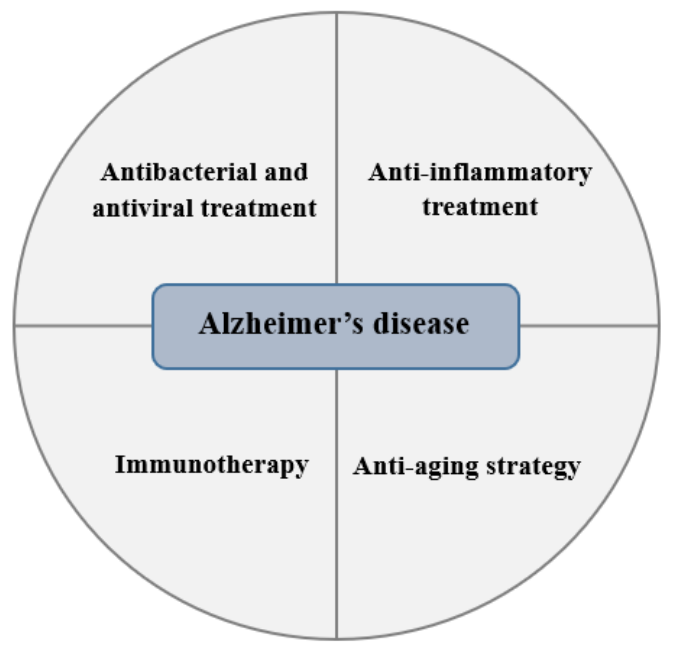

Figure 2. A close connection between immunosenescence and AD is increasingly recognized. New treatments for AD aiming at regulating immunosenescence may relieve neurodegeneration. As to the imbalance of barrier flora, chronic low-grade inflammation and aging, antibacterial, antiviral and anti-inflammatory treatment, immunotherapy, and anti-aging strategy may become new methods to treat AD.

\subsection{Anti-inflammatory treatment}

Consistent with the concept that inflamm-aging may induce or aggravate the pathogenesis of $\mathrm{AD}$, long-term administration of anti-inflammatory drugs may reduce the risk of $\mathrm{AD}$ [128]. However, clinical trials of nonsteroidal anti-inflammatory drugs (NSAIDs), such as Naproxen, Celecoxib and Rofecoxib showed no clinical benefit in the treatment of $\mathrm{AD}$ [129]. There are conflicting opinions about the use of NSAIDs in AD. Further Randomized Controlled Trials (RCTs) should be conducted with larger samples for a long duration to study the role of NSAIDs or other anti-inflammatory drugs in the treatment of $\mathrm{AD}$ [130].

\subsection{Immunotherapy}

Immunotherapies against $A \beta$ and tau are currently the main tested therapeutic approaches. According to the latest statistics in 2019, among the 132 agents in AD clinical trials, $40 \%$ of the drugs are aimed at ameliorating the amyloid pathology, of which 20 are monoclonal or biological therapies [131]. Seventeen percent have tau as the target,and there are ten biologics among anti-tau agents [131]. Moreover, a plethora of immunomodulators such as cytokines, complement components, and histocompatibility proteins are essential for functional synaptic formation [132]. However, it is still unclear whether boosting or suppressing the immune system, in the brain or the periphery, may reverse neurodegeneration in $\mathrm{AD}$ patients [133]. Whether immunotherapy can stimulate the infiltration of immune cells and factors into the brain to regulate inflammation needs further research to confirm.

\subsection{Anti-aging strategy}

In addition to a specific treatment, slowing down agerelated systemic decline will benefit AD. Researchers proposed that geroprotectors, compounds that slow the rate of biological aging, may reduce the incidence of $\mathrm{AD}$, which are likely to be novel AD drug candidates [134]. Animal experiments have confirmed that young blood can change the cognitive state of old mice [135]. A Phase I clinical trial using younger blood to improve mild to moderate cognitive impairment is considered safe and tolerable, and its effect is worth looking forward to [136]. As an anti-aging strategy,inhibition of mTOR ameliorates immunosenescence in old humans, and also suppresses brain aging to prevent neurodegeneration [137].

Table 2 lists the new drugs and their specific mechanisms for treating AD. The task to develop an effective treatment for $\mathrm{AD}$ is arduous, but strategies harnessing our knowledge of immunosenescence may become new methods to treat $\mathrm{AD}$.

\section{Conclusion}

Over the decades, there is enormous progress in describing the immune age-related alterations. With age, the inherent immune and adaptive immune defects increase the vulnerability of the immune system, which may lead to cognitive impairment [127]. Immunosenescence has emerged as a crucial player in the pathogenesis of $\mathrm{AD}$, but its functional role remains unclear.The new era forces us to explore how the neuroimmune system communicates with each other in the context of aging, and further decipher the effect of 
immunosenescence on the brain. Aiming at regulating the changes of the age-related immune barrier, eliminating aging immune cells, and fighting chronic inflammation, we will expand the research perspective of AD.

Table 2. Novel treatments for AD to reverse immunosenescence.

\begin{tabular}{|llll|}
\hline Drug classification & agent & Mechanism of action & Ref. \\
\hline Antimicrobial therapy & Antibiotic treatment & Avoid bacterial infections & {$[122]$} \\
\hline & Antiviral agent & Protects against virus infections & {$[125,126]$} \\
\hline & GV-971 & $\begin{array}{l}\text { Regulate gut flora imbalance and } \\
\text { reshape immune homeostasis }\end{array}$ & {$[124]$} \\
\hline $\begin{array}{l}\text { Anti-inflammatory } \\
\text { treatment }\end{array}$ & Anti-inflammatory drugs & Modulate inflammatory processes & {$[128]$} \\
\hline Immunotherapy & Antiamyloid agents & $\begin{array}{l}\text { Remove amyloid and prevent amyloid } \\
\text { production and aggregation }\end{array}$ & {$[131]$} \\
\hline & Anti-tau agents & Reduce tau-mediated neuronal damage & {$[131]$} \\
\hline immunomodulators & $\begin{array}{l}\text { cytokines, complement } \\
\text { components, and } \\
\text { histocompatibility proteins }\end{array}$ & Improve cell signaling & {$[132]$} \\
\hline Anti-aging strategy & Geroprotectors & Slow the rate of biological aging & {$[134]$} \\
\hline & Young blood & Modulate aging and rejuvenate organs & {$[135,136]$} \\
\hline & Inhibition of mTOR & Improve vaccine response & {$[137]$} \\
\hline
\end{tabular}

\section{Acknowledgments}

This work was supported by the National Natural Science Foundation of China (No. 81770833 and 81501212); the Hunan Province Special Health Research Projects (A2015-04).

\section{Conflict of interest}

Not applicable. The authors declare that they have no competing interests.

\section{References}

[1] Thal DR, Rüb U, Orantes M, Braak H (2002). Phases of A beta-deposition in the human brain and its relevance for the development of AD. Neurology, 58:1791-1800.

[2] Martorana A, Bulati M, Buffa S, Pellicanò M, Caruso $\mathrm{C}$, Candore G, et al. (2012). Immunosenescence, inflammation and Alzheimer's disease. Longev Healthspan, 1:8.

[3] Ricciarelli R, Fedele E (2017). The Amyloid Cascade Hypothesis in Alzheimer's Disease: It's Time to Change Our Mind. Curr Neuropharmacol, 15:926-935.

[4] Da Mesquita S, Ferreira AC, Sousa JC, Correia-Neves M, Sousa N, Marques F (2016). Insights on the pathophysiology of Alzheimer's disease: The crosstalk between amyloid pathology, neuroinflammation and the peripheral immune system. Neurosci Biobehav Rev, 68:547-562.

[5] RM M, MT H (2017). Role of neuroinfammation in neurodegeneration: New insights. Alzheimers Res Ther, 9:14.

[6] Solana C, Tarazona R, Solana R (2018). Immunosenescence of Natural Killer Cells, Inflammation, and Alzheimer's Disease. Int J Alzheimers Dis, 2018:1-9.

[7] C.Lopez-Otin, Blasco MA, L.Partridge, Serrano M, G.Kroemer (2013). The hallmarks of aging. Cell, 153:1194-1217.

[8] Balistreri CR, Candore G, Accardi G, ColonnaRomano G, Lio D (2013). NF-кB pathway activators as potential ageing biomarkers: targets for new therapeutic strategies. Immun Ageing, 10:24.

Hebert LE, Weuve J, Scherr PA, Evans DA (2013). Alzheimer disease in the United States (2010-2050) estimated using the 2010 census. Neurology, 80:1778.

[10] Jay TR, Hirsch AM, Broihier ML, Miller CM, Neilson LE, Ransohoff RM, et al. (2017). Disease ProgressionDependent Effects of TREM2 Deficiency in a Mouse Model of Alzheimer's Disease. J Neurosci, 37:637-647. Rubino G, Bulati M, Aiello A, Aprile S, Gambino CM, Gervasi F, et al. (2018). Sicilian centenarian offspring are more resistant to immune ageing. Aging Clin Exp Res, 31:125-133.

[12] Fulop T, Dupuis G, Baehl S, Le Page A, Bourgade K, Frost $\mathrm{E}$, et al. (2016). From inflamm-aging to immuneparalysis: a slippery slope during aging for immuneadaptation. Biogerontology, 17:147-157.

[13] Rosshart SP, Vassallo BG, Angeletti D, Hutchinson DS, Morgan AP, Takeda K, et al. (2017). Wild Mouse Gut Microbiota Promotes Host Fitness and Improves Disease Resistance. Cell, 171:1015-1028.

[14] Lagkouvardos I, Pukall R, Abt B, Foesel BrU, Meier- 
Kolthoff JP, Kumar N, et al. (2016). The Mouse Intestinal Bacterial Collection (miBC) provides hostspecific insight into cultured diversity and functional potential of the gut microbiota. J Nat Microbiol, $1: 16131$

[15] Diao H, Jiao AR, Yu B, Mao XB, Chen DW (2019). Gastric infusion of short-chain fatty acids can improve intestinal barrier function in weaned piglets. Genes Nutr, 14:4.

[16] Man AL, Gicheva N, Nicoletti C (2014). The impact of ageing on the intestinal epithelial barrier and immune system. Cell Immunol, 289:112-118.

[17] Nagpal R, Mainali R, Ahmadi S, Wang S, Yadav H (2018). Gut microbiome and aging: Physiological and mechanistic insights. Nutr Healthy Aging, 4:267-285.

[18] Pabst O CV, Hornef M (2016). Secretory IgA in the Coordination of Establishment and Maintenance of the Microbiota. Trends Immunol, 37:287-296.

[19] Novak N GE, Bieber T, Allam JP (2010). Human skin and oral mucosal dendritic cells as 'good guys' and 'bad guys' in allergic immune responses. Clin Exp Immunol, 161:28-33.

[20] Licastro F, Candore G, Lio D, Porcellini E, Caruso CJI, Ageing (2005). Innate immunity and inflammation in ageing: A key for understanding age-related diseases. Immun Ageing, 2:8.

[21] Phillips RJ, Powley TL (2007). Innervation of the gastrointestinal tract: Patterns of aging. Auton Neurosci, 136:0-19.

[22] Annaert P, Brouwers J, Bijnens A, Lammert F, Tack J, Augustijns P (2010). Ex vivo permeability experiments in excised rat intestinal tissue and in vitro solubility measurements in aspirated human intestinal fluids support age-dependent oral drug absorption. Eur J Pharm Sci, 39:15-22.

[23] Mitchell EL, Davis AT, Brass K, Dendinger M, Barner $\mathrm{R}$, Gharaibeh R, et al. (2017). Reduced intestinal motility, mucosal barrier function, and inflammation in aged monkeys. J Nutr Health Aging, 21:354-361.

[24] Odamaki T, Kato K, Sugahara H, Hashikura N, Takahashi S, Xiao J-z, et al. (2016). Age-related changes in gut microbiota composition from newborn to centenarian: a cross-sectional study. BMC Microbiol, 16:90.

[25] Scott KA, Ida M, Peterson VL, Prenderville JA, Moloney GM, Izumo T, et al. (2017). Revisiting Metchnikoff: Age-related alterations in microbiotagut-brain axis in the mouse. Brain Behav Immun, 65:20-32.

[26] Mohajeri MH, La Fata G, Steinert RE, Weber P (2018). Relationship between the gut microbiome and brain function. Nutr Rev, 76:481-496.

[27] Sampson TR, Debelius JW, Thron T, Janssen S, Shastri GG, Ilhan ZE, et al. (2016). Gut Microbiota Regulate Motor Deficits and Neuroinflammation in a Model of Parkinson's Disease. Cell, 167:1469-1480.

[28] Kim S, Kwon S-H, Kam T-I, Panicker N, Karuppagounder SS, Lee S, et al. (2019). Transneuronal Propagation of Pathologic alphaSynuclein from the Gut to the Brain Models
Parkinson's Disease. Neuron, 103:627-641.

[29] Vogt NM, Kerby RL, Dill-McFarland KA, Harding SJ, Merluzzi AP, Johnson SC, et al. (2017). Gut microbiome alterations in Alzheimer's disease. Sci Rep, 7:13537.

[30] Zhan X, Stamova B, Jin L-W, Decarli C, Phinney B, Sharp FR (2016). Gram-negative bacterial molecules associate with Alzheimer disease pathology. Neurology, 87:2324-2332.

[31] Van dH, Harm J., Burgmans S, Jansen JFA, van Osch MJP, van Buchem MA, et al. (2016). Blood-Brain Barrier Leakage in Patients with Early Alzheimer Disease. Radiology, 281:527-535.

[32] Jay S, Anirikh C, Alice P, Sonia K, Delphine M-R, Mojgan M, et al. (2017). Aging and sarcopenia associate with specific interactions between gut microbes, serum biomarkers and host physiology in rats. Aging (Albany NY), 9:1698-1714.

[33] Jain K, Parida S, Mangwani N, Dash HR (2013). Isolation and characterization of biofilm-forming bacteria and associated extracellular polymeric substances from oral cavity. Ann Microbiol, 63:15531562.

[34] Cao W, Zheng H (2018). Peripheral immune system in aging and Alzheimer's disease. Mol Neurodegener, 13:51.

[35] Ren C, Webster P, Finkel SE, Tower J (2007). Increased Internal and External Bacterial Load during Drosophila Aging without Life-Span Trade-Off. Cell Metab, 6:144-152.

[36] Ide M, Harris M, Stevens A, Sussams R, Holmes C (2016). Periodontitis and Cognitive Decline in Alzheimer's Disease. PLos One, 11:e0151081.

[37] Leira Y, Domínguez C, Seoane J, Seoane-Romero J, Pías-Peleteiro JM, Takkouche B, et al. (2017). Is Periodontal Disease Associated with Alzheimer's Disease? A Systematic Review with Meta-Analysis. Neuroepidemiology, 48:21-31.

[38] Dando SJ, Mackay-Sim A, Norton R, Currie BJ, St. John JA, Ekberg JAK, et al. (2014). Pathogens Penetrating the Central Nervous System: Infection Pathways and the Cellular and Molecular Mechanisms of Invasion. Clin Microbiol Rev, 27:691-726.

[39] Harris JA, West AK, Meng IC (2009). Olfactory ensheathing cells: Nitric oxide production and innate immunity. Glia, 57:1848-1857.

[40] Musumeci T, Pellitteri R, Spatuzza M, Puglisi G (2014). Nose-to-Brain Delivery: Evaluation of Polymeric Nanoparticles on Olfactory Ensheathing Cells Uptake. J Pharm Sci, 103:628-635.

[41] Gloor SM, Wachtel M, Bolliger MF, Ishihara $\mathrm{H}$, Landmann R, Frei K (2001). Molecular and cellular permeability control at the blood-brain barrier. Brain Res Rev, 36:258-264.

[42] Montagne A, Barnes SR, Sweeney MD, Halliday MR, Sagare AP, Zhao Z, et al. (2015). Blood-Brain Barrier Breakdown in the Aging Human Hippocampus. Neuron, 85:296-302.

[43] Nation DA, Sweeney MD, Montagne A, Sagare AP, D'Orazio LM, Pachicano M, et al. (2019). Blood-brain 
barrier breakdown is an early biomarker of human cognitive dysfunction. Nat Med, 25:270-276.

[44] Abbott NJ, Patabendige AAK, Dolman DEM, Yusof SR, Begley DJ (2010). Structure and function of the blood-brain barrier. Neurobiol Dis, 37:13-25.

[45] Lee P, Kim J, Williams R, Sandhir R, Gregory E, Brooks WM, et al. (2012). Effects of aging on blood brain barrier and matrix metalloproteases following controlled cortical impact in mice. Exp Neurol, 234:50-61.

[46] Michela D, Jäggle M, Graziella R (2015). Immune aging, dysmetabolism, and inflammation in neurological diseases. Front Neurosci, 9:172.

[47] Togo T, Akiyama H, Iseki E, Kondo H, Ikeda K, Kato $\mathrm{M}$, et al. (2002). Occurrence of T cells in the brain of Alzheimer's disease and other neurological diseases. J Neuroimmunol, 124:83-92.

[48] Di Benedetto S, Mueller L, Wenger E, Duezel S, Pawelec G (2017). Contribution of neuroinflammation and immunity to brain aging and the mitigating effects of physical and cognitive interventions. Neurosci Biobehav Rev, 75:114-128.

[49] Festoff BW, Sajja RK, van Dreden P, Cucullo L (2016). HMGB1 and thrombin mediate the blood-brain barrier dysfunction acting as biomarkers of neuroinflammation and progression to neurodegeneration in Alzheimer's disease. J Neuroimmunol, 13:194.

[50] Storck SE, M.S. HA, Jessica B, Andrea W, André K, Anne M, et al. (2018). The concerted amyloid-beta clearance of LRP1 and ABCB1/P-gp across the bloodbrain barrier is linked by PICALM. Brain Behav Immun, 73:21-33.

[51] Assema DM, Lubberink M, Boellaard R, Schuit RC, Windhorst AD, Scheltens P, et al. (2012). PGlycoprotein Function at the Blood-Brain Barrier: Effects of Age and Gender. Mol Imaging Biol, 14:771-776

[52] Chiu CM, M.C.; Monahan, R.; Osgood, D.P.; Stopa, E.G.; Silverberg, G.D. (2015). P-glycoprotein expression and amyloid accumulation in human aging and Alzheimer's disease: Preliminary observations. Neurobiol Aging, 36:2475-2482.

[53] Hoffman JD, Parikh I, Green SJ, Chlipala G, Mohney RP, Keaton M, et al. (2017). Age Drives Distortion of Brain Metabolic, Vascular and Cognitive Functions, and the Gut Microbiome. Front Aging Neurosci, 9:298 Donahue JE, Flaherty SL, Johanson CE, Duncan JA, Silverberg GD, Miller MC, et al. (2006). RAGE, LRP1 , and amyloid-beta protein in Alzheimer's disease. Acta Neuropathol, 112:405-415.

[55] Patching SG (2017). Glucose Transporters at the Blood-Brain Barrier: Function, Regulation and Gateways for Drug Delivery. Mol Neurobiol, 54:10461077.

[56] Sweeney MD, Montagne A, Sagare AP, Nation DA, Schneider LS, Chui HC, et al. (2019). Vascular dysfunction-The disregarded partner of Alzheimer's disease. Alzheimers Dement, 15:158-167.

[57] Ding F, Yao J, Rettberg JR, Chen S, Brinton RD (2013).
Early Decline in Glucose Transport and Metabolism Precedes Shift to Ketogenic System in Female Aging and Alzheimer's Mouse Brain: Implication for Bioenergetic Intervention. PLos One, 8:e79977.

[58] Bonte S, Vandemaele P, Verleden S, Audenaert K, Deblaere K, Goethals I, et al. (2017). Healthy brain ageing assessed with 18F-FDG PET and agedependent recovery factors after partial volume effect correction. Eur J Nucl Med Mol Imaging, 44:838-849.

[59] Jiang T, Yin F, Yao J, Brinton RD, Cadenas E (2013). Lipoic acid restores age-associated impairment of brain energy metabolism through the modulation of Akt/JNK signaling and PGC1 alpha transcriptional pathway. Aging Cell, 12:1021-1031.

[60] Schwartz M, Deczkowska A (2016). Neurological Disease as a Failure of Brain-Immune Crosstalk: The Multiple Faces of Neuroinflammation. Trends Immunol, 37:668-679.

[61] Baruch K, Ron-Harel N, Gal H, Deczkowska A, Shifrut E, Ndifon W, et al. (2013). CNS-specific immunity at the choroid plexus shifts toward destructive Th2 inflammation in brain aging. Proc Natl Acad Sci U S A, 110:2264-2269.

[62] Baruch K, Schwartz M (2013). CNS-specific T cells shape brain function via the choroid plexus. Brain Behav Immun, 34:11-16.

[63] Baruch K, Deczkowska A, David E, Castellano JM, Miller O, Kertser A, et al. (2014). Aging-induced type I interferon response at the choroid plexus negatively affects brain function. Science, 346:89-93.

[64] Baruch K, Rosenzweig N, Kertser A, Deczkowska A, Schwartz M (2015). Breaking immune tolerance by targeting Foxp3+ regulatory $\mathrm{T}$ cells mitigates Alzheimer's disease pathology. Nat Commun, 6:7967.

[65] Kunis G, Baruch K, Miller O, Schwartz M (2015). Immunization with a Myelin-Derived Antigen Activates the Brain's Choroid Plexus for Recruitment of Immunoregulatory Cells to the CNS and Attenuates Disease Progression in a Mouse Model of ALS. J Neurosci, 35:6381-6393.

[66] Baruch K, Deczkowska A, Rosenzweig N, TsitsouKampeli A, Sharif AM, Matcovitch-Natan O, et al. (2016). PD-1 immune checkpoint blockade reduces pathology and improves memory in mouse models of Alzheimer's disease. Nat Med, 22:135-137.

[67] Schwartz M, Baruch K (2014). The resolution of neuroinflammation in neurodegeneration: leukocyte recruitment via the choroid plexus. EMBO J, 33:7-22.

[68] Page AL, Dupuis G, Frost EH, Larbi A, Pawelec G, Witkowski JM, et al. (2017). Role of the peripheral innate immune system in the development of Alzheimer's disease. Exp Gerontol, 107:59-66.

[69] Rawji KS, Mishra MK, Michaels NJ, Rivest S, Stys PK, Yong VW (2016). Immunosenescence of microglia and macrophages: impact on the ageing central nervous system. Brain, 139:653-661.

[70] Damani MR, Zhao L, Fontainhas AM, Amaral J, Fariss RN, Wong WT (2011). Age-related alterations in the dynamic behavior of microglia. Aging Cell, 10:263276. 
[71] Floden AM, Combs CK (2011). Microglia Demonstrate Age-Dependent Interaction with Amyloid-beta Fibrils. J Alzheimers Dis, 25:279-293.

[72] Sierra A, Gottfried-Blackmore AC, McEwen BS, Bulloch K (2007). Microglia derived from aging mice exhibit an altered inflammatory profile. Glia, 55:412424.

[73] Njie EG, Boelen E, Stassen FR, Steinbusch HWM, Borchelt DR, Streit WJ (2012). Ex vivo cultures of microglia from young and aged rodent brain reveal age-related changes in microglial function. Neurobiol Aging, 33:195.e191-112.

[74] Babcock AA, llkjær L, H.Clausen B, Villadsen B, Dissing-Olesen L, Bendixen ATM, et al. (2015). Cytokine-producing microglia have an altered betaamyloid load in aged APP/PS1 Tg mice. Brain Behav Immun, 48:86-101.

[75] Fan H, Wu P-F, Zhang L, Hu Z-L, Wang W, Guan XL, et al. (2015). Methionine Sulfoxide Reductase A Negatively Controls Microglia-Mediated Neuroinflammation via Inhibiting ROS/MAPKs/NF$\kappa \mathrm{B}$ Signaling Pathways Through a Catalytic Antioxidant Function. Antioxid Redox Signal, 22:832847.

[76] Regen F, Hellmann-Regen J, Costantini E, Reale M (2017). Neuroinflammation and Alzheimer's Disease: Implications for Microglial Activation. Curr Alzheimer Res, 14:1140-1148.

[77] Perry VH, Teeling J (2013). Microglia and macrophages of the central nervous system: the contribution of microglia priming and systemic inflammation to chronic neurodegeneration. Semin Immunopathol, 35:601-612.

[78] Ruckh JM, Zhao JW, Shadrach JL, van Wijngaarden P, Rao TN, Wagers AJ, et al. (2012). Rejuvenation of Regeneration in the Aging Central Nervous System. Cell Stem Cell, 10:96-103.

[79] Cronk JC, Filiano AJ, Louveau A, Marin I, Marsh R, Ji E, et al. (2018). Peripherally derived macrophages can engraft the brain independent of irradiation and maintain an identity distinct from microglia. J Exp Med, 215:1627-1647.

[80] Simard AR, Soulet D, Gowing G, Julien JP, Rivest S (2006). Bone Marrow-Derived Microglia Play a Critical Role in Restricting Senile Plaque Formation in Alzheimer's Disease. Neuron, 49:489-502.

[81] Saresella M, Marventano I, Calabrese E, Piancone F, Clerici M (2013). A Complex Proinflammatory Role for Peripheral Monocytes in Alzheimer's Disease. J Alzheimers Dis, 38:403-413.

[82] Solana R, Tarazona R, Gayoso I, Lesur O, Dupuis G, Fulop $T$ (2012). Innate immunosenescence: Effect of aging on cells and receptors of the innate immune system in humans. Semin Immunol, 24:331-341.

[83] Linton PJ, Thoman ML (2014). Immunosenescence in monocytes, macrophages, and dendritic cells: Lessons learned from the lung and heart. Immunol Lett, 162:290-297.

[84] Franceschi C, Bonafe M, Valensin S, Olivieri F, De Luca M, Ottaviani E, et al. 2000. Inflamm-aging: An evolutionary perspective on immunosenescence. Ann N Y Acad Sci. 244-254.

[85] Panda A, Arjona A, Sapey E, Bai F, Fikrig E, Montgomery RR, et al. (2009). Human innate immunosenescence: causes and consequences for immunity in old age. Trends Immunol, 30:325-333.

[86] Fauriat C, Long EO, Ljunggren HG, Bryceson YT (2009). Regulation of human NK-cell cytokine and chemokine production by target cell recognition. Blood, 115:2167-2176.

[87] Cooper MA, Fehniger TA, Caligiuri MA (2001). The biology of human natural killer-cell subsets. Trends Immunol, 22:633-640.

[88] Maté I, Cruces J, Giménez-Llort L, De IFM (2015). Function and redox state of peritoneal leukocytes as preclinical and prodromic markers in a longitudinal study of triple-transgenic mice for Alzheimer's disease. J Alzheimers Dis, 43:213-226.

[89] Page AL, Bourgade K, Lamoureux J, Frost E, Pawelec G, Larbi A, et al. (2015). NK Cells are Activated in Amnestic Mild Cognitive Impairment but not in Mild Alzheimer's Disease Patients. J Alzheimers Dis, 46:93-107.

[90] Ridker PM, Everett BM, Thuren T, MacFadyen JG, Chang WH, Ballantyne C, et al. (2017). Antiinflammatory Therapy with Canakinumab for Atherosclerotic Disease. N Engl J Med, 377:11191131.

[91] Späni C, Suter T, Derungs R, Ferretti MT, Kulic L (2015). Reduced $\beta$-amyloid pathology in an APP transgenic mouse model of Alzheimer's disease lacking functional B and T cells. Acta Neuropathol Com, 3:71.

[92] Anderson KM, Olson KE, Estes KA, Flanagan K, Gendelman HE, Mosley RL (2014). Dual destructive and protective roles of adaptive immunity in neurodegenerative disorders. Transl neurodegener, $3: 25$.

[93] Filiano AJ, Xu Y, Tustison NJ, Marsh RL, Baker W, Smirnov I, et al. (2016). Unexpected role of interferon-gamma in regulating neuronal connectivity and social behaviour. Nature, 535:425-429.

[94] Derecki NC, Cardani AN, Yang CH, Quinnies KM, Crihfield A, Lynch KR, et al. (2010). Regulation of learning and memory by meningeal immunity: a key role for IL-4. J Exp Med, 207:1067-1080.

[95] Cheung P, Vallania F, Warsinske HC, Donato M, Schaffert S, Chang SE, et al. (2018). Single-Cell Chromatin Modification Profiling Reveals Increased Epigenetic Variations with Aging. Cell, 173:13851397.

[96] Weng NP (2006). Aging of the Immune System: How Much Can the Adaptive Immune System Adapt? Immunity, 24:495-499.

[97] Monsonego A, Zota V, Karni A, Krieger JI, Bar-Or A, Bitan G, et al. (2003). Increased T cell reactivity to amyloid beta protein in older humans and patients with Alzheimer disease. J Clin Invest, 112:415-422.

[98] Wang F, Shen XY, Li SP, Chen L, Wang YR, Qin J, et al. (2015). Splenocytes derived from young WT mice 
prevent AD progression in APPswe/PSENldE9 transgenic mice. Oncotarget, 6:1-12.

[99] Baruch K, Rosenzweig N, Kertser A, Deczkowska A, Sharif AM, Spinrad A, et al. (2015). Breaking immune tolerance by targeting Foxp3(+) regulatory $\mathrm{T}$ cells mitigates Alzheimer's disease pathology. Nat Commun, 6:7967.

[100] Gendelman HE, Mosley RL (2015). A Perspective on Roles Played by Innate and Adaptive Immunity in the Pathobiology of Neurodegenerative Disorders. J Neuroimmune Pharm, 10:645-650.

[101] Wang F, Liu H, Shen X, Ao H, Gao L, Chen L, et al. (2015). The combined treatment of amyloid- $\beta 1-42-$ stimulated bone marrow-derived dendritic cells plus splenocytes from young mice prevents the development of Alzheimer's disease in APPswe/PSENldE9 mice. Neurobiol Aging, 36:111122.

[102] Costantini E, D'Angelo C, Reale M (2018). The Role of Immunosenescence in Neurodegenerative Diseases. Mediat Inflamm, 2018:1-12.

[103] Buffa S, Bulati M, Pellicano M, Dunn-Walters DK, $\mathrm{Wu}$ Y-C, Candore G, et al. (2011). B cell immunosenescence: different features of naive and memory B cells in elderly. Biogerontology, 12:473483.

[104] Bagnara D, Squillario M, Kipling D, Mora T, Walczak AM, Da Silva L, et al. (2015). A Reassessment of IgM Memory Subsets in Humans. J Immunol, 195:37163724.

[105] Busse M, Michler E, Von Hoff F, Dobrowolny H, Hartig R, Frodl T, et al. (2017). Alterations in the Peripheral Immune System in Dementia. J Alzheimers Dis, 58:1303-1313.

[106] Qu BX, Gong YH, Moore C, Fu M, German DC, Chang LY, et al. (2014). Beta-amyloid auto-antibodies are reduced in Alzheimer's disease. J Neuroimmunol, 274:168-173

[107] Gold M, Mengel D, Roskam S, Dodel R, Bach JP (2013). Mechanisms of action of naturally occurring antibodies against beta-amyloid on microglia. J Neuroinflamm, 10:5.

[108] Britschgi M, Olin CE, Johns HT, Takeda-Uchimura Y, LeMieux MC, Rufibach K, et al. (2009). Neuroprotective natural antibodies to assemblies of amyloidogenic peptides decrease with normal aging and advancing Alzheimer's disease. P Natl Acad Sci U S A, 106:12145-12150.

[109] Piazza F, Greenberg SM, Savoiardo M, Gardinetti M, Difrancesco JC (2013). Anti-amyloid $\beta$ autoantibodies in cerebral amyloid angiopathy-related inflammation: Implications for Amyloid-Modifying Therapies. Ann Neurol, 73:449-458.

[110] Chovatiya R, Medzhitov R (2014). Stress, Inflammation, and Defense of Homeostasis. Mol Cell, 54:281-288.

[111] Shanley DP, Aw D, Manley NR, Palmer DB (2009). An evolutionary perspective on the mechanisms of immunosenescence. Trends Immunol, 30:0-381.

[112] Qin L, Jing X, Qiu Z, Cao W, Jiao Y, Routy J-P, et al.
(2016). Aging of immune system: Immune signature from peripheral blood lymphocyte subsets in 1068 healthy adults. Aging-Us, 8:848-859.

[113] Chen Y, Liu S, Leng SX (2019). Chronic Low-grade Inflammatory Phenotype (CLIP) and Senescent Immune Dysregulation. Clin Ther, 41:400-409.

[114] Stenfors CUD, Jonsdottir IH, Hanson LLM, Theorell $\mathrm{T}$ (2017). Associations between systemic proinflammatory markers, cognitive function and cognitive complaints in a population-based sample of working adults. J Psychosom Res, 96:49-59.

[115] Walker KA, Hoogeveen RC, Folsom AR, Ballantyne CM, Knopman DS, Windham BG, et al. (2017). Midlife systemic inflammatory markers are associated with late-life brain volume The ARIC study. Neurology, 89:2262-2270.

[116] Gisondi P, Sala F, Alessandrini F, Avesani V, Zoccatelli G, Beltramello A, et al. (2014). Mild Cognitive Impairment in Patients with Moderate to Severe Chronic Plaque Psoriasis. Dermatology, 228:78-85.

[117] MacPherson KP, Sompol P, Kannarkat GT, Chang J, Sniffen L, Wildner ME, et al. (2017). Peripheral administration of the soluble TNF inhibitor XPro1595 modifies brain immune cell profiles, decreases betaamyloid plaque load, and rescues impaired long-term potentiation in 5xFAD mice. Neurobiol Dis, 102:8195.

[118] Fulop T, Witkowski JM, Bourgade K, Khalil A, Zerif E, Larbi A, et al. (2018). Can an Infection Hypothesis Explain the Beta Amyloid Hypothesis of Alzheimer's Disease? Front Aging Neurosci, 10:224.

[119] Fulop T, Itzhaki RF, Balin BJ, Miklossy J, Barron AE (2018). Role of Microbes in the Development of Alzheimer's Disease: State of the Art - An International Symposium Presented at the 2017 IAGG Congress in San Francisco. Front Genet, 9:362.

[120] Balin BJ, Hudson AP (2018). Herpes viruses and Alzheimer's disease: new evidence in the debate. Lancet Neurol, 17:839-841.

[121] Kumar DKV, Choi SH, Washicosky KJ, Eimer WA, Tucker S, Ghofrani J, et al. (2016). Amyloid-beta peptide protects against microbial infection in mouse and worm models of Alzheimer's disease. Sci Transl Med, 8:340ra72.

[122] Minter MR, Zhang C, Leone V, Ringus DL, Sisodia SS (2016). Antibiotic-induced perturbations in gut microbial diversity influences neuro-inflammation and amyloidosis in a murine model of Alzheimer's disease. Sci Rep, 6:30028.

[123] Kowalski K, Mulak A (2019). Brain-Gut-Microbiota Axis in Alzheimer's Disease. J Neurogastroenterol Motil, 25:48-60.

[124] Wang X, Sun G, Feng T, Zhang J, Huang X, Wang T, et al. (2019). Sodium oligomannate therapeutically remodels gut microbiota and suppresses gut bacterial amino acids-shaped neuroinflammation to inhibit Alzheimer's disease progression. Cell Res, 29:787-803.

[125] Tzeng NS, Chung CH, Lin FH, Chiang CP, Chien WCJN (2018). Anti-herpetic Medications and Reduced Risk of Dementia in Patients with Herpes 
Simplex Virus Infections - a Nationwide, PopulationBased Cohort Study in Taiwan. Neurotherapeutics, 15:417-429.

[126] Chen CH, Wu SI, Huang KY, Yang YH, Gossop MJJoCP (2017). Herpes Zoster and Dementia: A Nationwide Population-Based Cohort Study. J Clin Psychiatry, 79.

[127] Panza F, Lozupone M, Solfrizzi V, Watling M, P.Imbimbo B (2019). Time to test antibacterial therapy in Alzheimer's disease. Brain, 142:2905-2929.

[128] McGeer PL, Rogers J, McGeer EG (2006). Inflammation, anti-inflammatory agents and Alzheimer disease: The last 12 years. J Alzheimers Dis, 9:271-276.

[129] Ozben T, Ozben S (2019). Neuro-inflammation and anti-inflammatory treatment options for Alzheimer's disease. Clin Biochem, 72:87-89.

[130] Ali MM, Ghouri RG, Ans AH, Akbar A, Toheed A (2019). Recommendations for Anti-inflammatory Treatments in Alzheimer's Disease: A Comprehensive Review of the Literature. Cureus, 11:e4620.

[131] Cummings J, Lee G, Ritter A, Sabbagh M, Zhong K
(2019). Alzheimer's disease drug development pipeline: 2019. Alzheimers Dement (N Y), 5:272-293.

[132] Boulanger LM (2009). Immune Proteins in Brain Development and Synaptic Plasticity. Neuron, 64:93109.

[133] Liu Y, Aguzzi A (2019). Immunotherapy for neurodegeneration? Science, 364:130-131.

[134] Schubert D, Currais A, Goldberg J, Finley K, Petrascheck M, Maher P (2018). Geroneuroprotectors: Effective Geroprotectors for the Brain. Trends Pharmacol Sci, 39:1004-1007.

[135] Wyss-Coray T (2016). Ageing, neurodegeneration and brain rejuvenation. Nature, 539:180-186.

[136] Sha SJ, Deutsch GK, Tian L, Richardson K, Coburn M, Gaudioso JL, et al. (2019). Safety, Tolerability, and Feasibility of Young Plasma Infusion in the Plasma for Alzheimer Symptom Amelioration Study A Randomized Clinical Trial. Jama Neurol, 76:35-40.

[137] Mannick JB, Del Giudice G, Lattanzi M, Valiante NM, Praestgaard J, Huang BS, et al. (2014). mTOR inhibition improves immune function in the elderly. Sci Transl Med, 6:268ra179. 